\title{
Monstros adaptados: do livro $A$ arte de Tim Burton ao espaço expositivo $A$ Beleza Sombria dos Monstros
}

\section{Adapted Monsters: from the book $A$ arte de Tim Burton to the exhibition A Beleza Sombria dos Monstros}

Rodrigo Corrêa Gontijo*

Paulo Edson Alves Filho**

\footnotetext{
* Docente no curso de Comunicação e Multimeios da Universidade Estadual de Maringá. Doutor em Multimeios pelo Instituto de Artes da UNICAMP. E-mail: rcgontijo@uem.br

"Docente do curso de Letras da Universidade de Sorocaba - UNISO. Doutor em Língua Inglesa e Literaturas Inglesa e Norte-americana pela FFLCH/USP. E-mail: paulo.alves@prof.uniso.br

TradTerm, São Paulo, v.38, fevereiro/2021, p. 194-216

Número Especial - III JOTA 
Resumo: Este trabalho tem por objetivo discorrer sobre a transposição de personagens do livro The Art of Tim Burton (2009) para a exposição A Beleza Sombria dos Monstros, recriados em máquinas de visualização inspiradas no pré-cinema. Para a análise, serão utilizadas as teorias da adaptação de Linda Hutcheon (2006), intermidialidade e transmidialidade, de Chiel Kattenbelt (2008) e remediação, de Bolter e Grusin (2000), visando evidenciar suas nuances artísticas em relação às obras originais.

Palavras-chave: Tim Burton; Adaptação; Intermidialidade; Remediação; The Art of Tim Burton; A Beleza Sombria dos Monstros

Abstract: This work aims to discuss the transposition of characters from the book The Art of Tim Burton (2009) into the exhibition A Beleza Sombria dos Monstros, recreated into visual machines inspired on pre-cinema. For the analysis, the theory of adaptation by Linda Hutcheon (2006), intermediality and remediation by Chiel Kattenbelt (2008), and remediation, by Bolter and Grusin (2000) will be used in order to highlight their artistic nuances in relation to the original works.

Keywords: Tim Burton; Adaptation; Intermediality; Remediation; The Art of Tim Burton; A Beleza Sombria dos Monstros 


\section{A exposição A Beleza Sombria dos Monstros: 10 anos da Arte de Tim Burton}

A produtora brasileira Rua 34, através do edital do Centro Cultural Banco do Brasil, organizou a exposição sobre a carreira de Tim Burton a partir do livro The Art of Tim Burton (Burton et al., Steeles Publishing, 2009) com uma série de ilustrações de personagens do cineasta. Adaptado do livro, o projeto Beleza Sombria dos Monstros: 10 anos da Arte de Tim Burton teve curadoria de Jenny He, curadora independente do MOMA - Museu de Arte Moderna de Nova lorque, Holly Kempf, designer que colabora há mais de uma década com os projetos do cineasta norte-americano e produção executiva de Leo Rea Lé. A exposição esteve em cartaz no CCBB de Brasília de 28 de maio a 11 de agosto de 2019.

Este artigo pretende discorrer sobre a transposição dos personagens do primeiro capítulo do livro de Burton em sala expositiva, realizado por artistas brasileiros.

\section{Tim Burton e seus Monstros Incompreendidos}

Tim Burton sempre teve um apreço pelos monstros. Fã dos filmes de terror e ficção científica que a Universal Pictures produziu durante as décadas de 1930 a 1950, como Drácula (com Bela Lugosi) e Frankenstein (com Boris Karloff), Burton desenhava seres imaginários nos cadernos escolares e, com o passar do tempo, de maneira apressada e crua, em guardanapos de papel dos restaurantes e bares que frequentava (BURTON 2015). Desta arte em processo, nas telas improvisadas e manchadas por comida e bebida, surgiram criações que décadas mais tarde ganhariam as telas de cinema.

Seus monstros, na maioria das vezes, se constituem por humanoides abarcando o que José Gil considera "uma zona de essências difusas de seres cada vez mais numerosos e variados” (GIL 2000: 169). São humanos que, nos seus limites extremos, incorporam dimensões animalescas ou níveis de deformação físicas e mentais que poderiam protagonizar espetáculos macabros dos antigos circos de horror do final do século XIX, ou seja, monstros que não se situam "fora do domínio humano: encontram-se no seu limite" (GIL 2000: 170).

TradTerm, São Paulo, v.38, fevereiro/2021, p. 194-216

Número Especial - III JOTA

www.revistas.usp.br/tradterm 
Os monstros de Tim Burton não são divinos, não detém poderes sobrenaturais e não são seres míticos de florestas encantadas. Os personagens por ele criados carregam animalidades que se mesclam com humanidades, são 'aberrações da realidade', conforme a definição de Gil (2000: 174), atravessadas por sentimentos como a melancolia, tristeza, ódio, angústia e medo. São monstros teratológicos que assinalam nossos limites enquanto seres humanos. Segundo o autor,

nós exigimos mais dos monstros, pedimos-lhes, justamente, que nos inquietem, que nos provoquem vertigens, que abalem permanentemente as nossas mais sólidas certezas; porque necessitamos de certezas sobre a nossa identidade humana ameaçada de indefinição. Os monstros, felizmente, existem não para nos mostrar o que não somos, mas o que poderíamos ser. Entre estes dois polos, entre uma possibilidade negativa e um acaso possível, tentamos situar a nossa humanidade de homens (GIL 2000: 168).

O mito de Frankenstein invade o imaginário de Burton na criação de monstros artificiais de carne e osso como Edward Scissorhands (1990), inventado por um velho cientista que morre antes de finalizar seu feito deixando-o com enormes tesouras no lugar das mãos. Esta fábula reaparece também em Frankenweenie (2012) através do personagem Sparky, um animal humanizado (na forma como se comporta e demonstra seus sentimentos), que morre ao ser atropelado. Porém, seu dono, o garoto Victor Frankenstein, revoltado com o acidente, se utiliza dos conhecimentos aprendidos na escola durante as aulas de física para trazer Sparky de volta à vida, todo costurado e cheio de cicatrizes, com marcas que lembram o clássico personagem dos filmes da Universal Pictures interpretado por Boris Karloff. Burton também desenha monstros derivados dos “sonhos mais antigos do devir-animal xamânico" (GIL 2000: 169), tais como: um homem-morcego (Batman, 1989), que trava constantes embates contra seus inimigos, Catwoman e Penguin (Batman Returns, 1992). Os monstros atormentados aparecem na figura do garotinho Vincent Malloy (Vincent, 1982), que, enquanto sonha em ser Vincent Prince (ator de filmes de terror, também narrador da própria animação), vê o mundo distorcido com sombras anguladas habitados por aranhas e morcegos. O mesmo ocorre com o personagem Sweeney Todd (Sweeney Todd: the Demon Barber of Fleet Street, 2007): um barbeiro serial-killer que, transtornado

TradTerm, São Paulo, v.38, fevereiro/2021, p. 194-216

Número Especial - III JOTA www.revistas.usp.br/tradterm 
por um sentimento de vingança, executa seus clientes a golpes de navalha. $\mathrm{Na}$ contramão dos monstros-atormentados, temos aqueles que reconhecem suas monstruosidades e querem abandoná-las, deixando de ser o que realmente são. É o caso de Jack Skellington (The Nightmare Before Christmas, 1993), o homem esqueleto que veste terno listrado e usa gravata no formato de morcego. Ele é sensível, recita Shakespeare e, cansado de assustar as pessoas no Halloween, entra em conflito ao descobrir a festa de Natal quando encanta-se com os sentimentos alegres que por ali permeiam. As criaturas de Burton inevitavelmente nos remetem ao questionamento de Gil (2000: 176-177):

O que faz do monstro um "atractor" (da imaginação)? O fato de se situar numa fronteira indecisa entre a humanidade e a não-humanidade. Melhor: o nascimento monstruoso mostraria como potencialmente a humanidade do homem, configurada no corpo normal, contém o germe da sua inumanidade. Qualquer coisa em nós, no mais íntimo de nós - no nosso corpo, na nossa alma, no nosso ser - nos ameaça de dissolução e caos. Qualquer coisa de imprevisível e pavoroso, de certo modo pior do que uma doença e do que a morte (pois é não-forma, não-vida na vida), permanece escondido mas pronto a manifestar-se. A fronteira para além da qual se desintegra a nossa identidade humana está traçada dentro de nós, e não sabemos onde.

Figura 1: Montagem com desenhos realizados por Tim Burton: 1.Edward Scissorhands, 2.Sparky, 3.Vincent, 4.Sweeney Todd, 5.Batman, 6.Catwoman, 7.Penguin, 8. Jack Skellington ${ }^{1}$

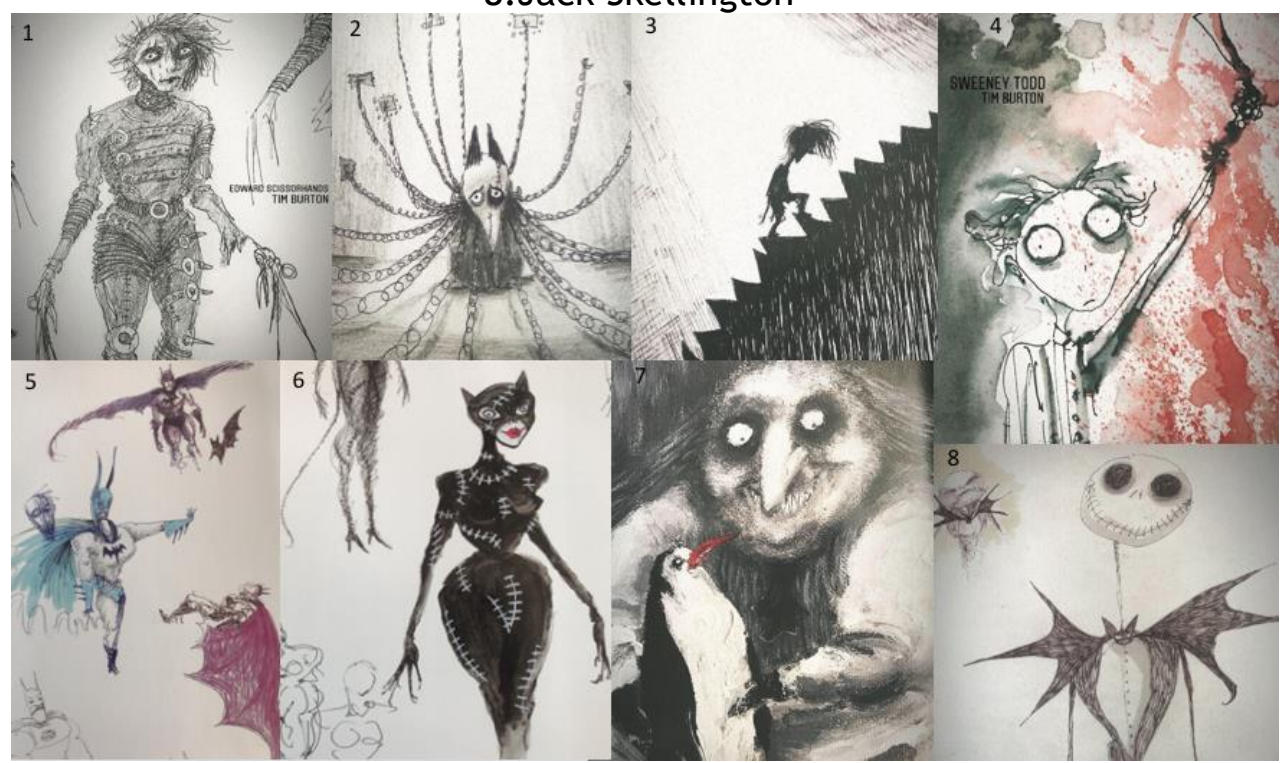

\footnotetext{
${ }^{1}$ Fonte: Burton et al., The Art of Tim Burton. Steeles Publishing, 2009

TradTerm, São Paulo, v.38, fevereiro/2021, p. 194-216

Número Especial - III JOTA

www.revistas.usp.br/tradterm
} 
Os monstros burtonianos descritos acima compõem o capítulo "Monstros Incompreendidos" do livro The Art of Tim Burton (2009). A proposta de transpô-los para um espaço expositivo surgiu, conforme aponta Leo Rea Lé, produtor executivo da exposição, "de uma necessidade prática: criar uma proposta de exposição que não contemplasse o acervo do artista”. Assim o livro, indicado por Jenny He, curadora associada do escritório de Tim Burton, foi analisado cuidadosamente para que as imagens pudessem emergir, já que "a exposição devia ser imaginada a partir da ação de libertar suas criaturas no espaço" ${ }^{2}$. Dessa forma, as ilustrações no livro foram transformadas em engenhocas e traquitanas inspiradas no précinema que proporcionaram a elas a ilusão do movimento.

\section{Uma jornada pelo pré-cinema}

0 artista, professor e pesquisador no campo do cinema experimental e expandido Rodrigo Gontijo foi convidado para trabalhar com os personagens do primeiro capítulo do livro The Art of Tim Burton, juntamente com uma equipe formada por Maurício Jabur (desenvolvimento tecnológico), Márcia Porto (ilustrações), Agnaldo Pinho (bonecos), Pedro Febrônio (artefatos e arte) e Paulo Emílio (assistência geral), e levá-los ao espaço expositivo. Tendo em vista que Tim Burton realizou alguns destes filmes utilizando-se da técnica stopmotion, empregada nos primórdios da animação, a origem da imagem em movimento foi revisitada através de peças mecanizadas em aparelhos que produziam a ilusão do movimento. As ilustrações, transformadas em filmes de suspense e fantasia, retrocederam mais de um século e foram convertidas em brinquedos óticos inspirados no pré-cinema. Cada uma das invenções citadas abaixo foi resgatada, ressignificada e incorporada à exposição.

O cinema, mesmo antes de seu surgimento oficial em 1895, remonta a artistas, sonhadores e inventores e, também, ao teatro de sombra criado pelo imperador $\mathrm{Wu} \mathrm{Ti} \mathrm{-} \mathrm{em} \mathrm{torno} \mathrm{do} \mathrm{ano} \mathrm{de} 121$ a.C. - para dar vida a sua bailarina favorita que acabara de falecer. Os enredos contados pelos operadores, que

\footnotetext{
2 Lé, Leo Rea. Entrevista realizada com Leo Rea Lé em 04/09/2020 por Rodrigo Gontijo. Leo Rea Lé foi o produtor executivo da exposição Beleza Sombria dos Monstros: 10 anos da Arte de Tim Burton.
}

TradTerm, São Paulo, v.38, fevereiro/2021, p. 194-216

Número Especial - III JOTA

www.revistas.usp.br/tradterm 
manipulavam figuras de madeira e couro diante de uma fonte de luz, geralmente abordavam reinos distantes, guerreiros e monstros mitológicos.

Figura 2: teatro de sombras chinês ${ }^{3}$

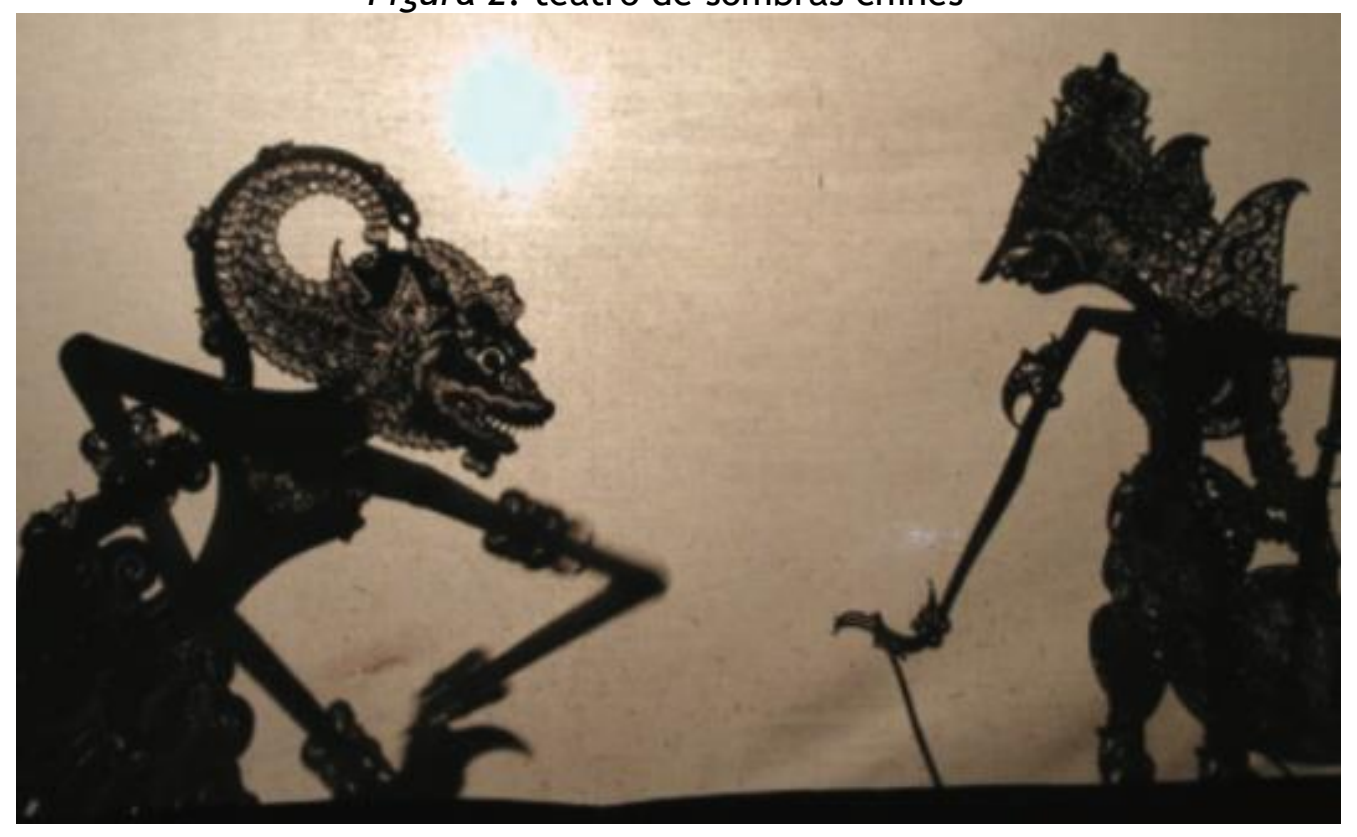

Ainda na China antiga, surgiam os jogos de distorções com superfícies lisas e polidas que refletiam imagens. As anamorfoses promovidas por espelhos côncavos, convexos e cilíndricos foram retomadas na Europa do século XV por pintores renascentistas que forjavam a perspectiva visual em seus quadros, murais e afrescos.

Figura 3: anamorfose. ${ }^{4}$

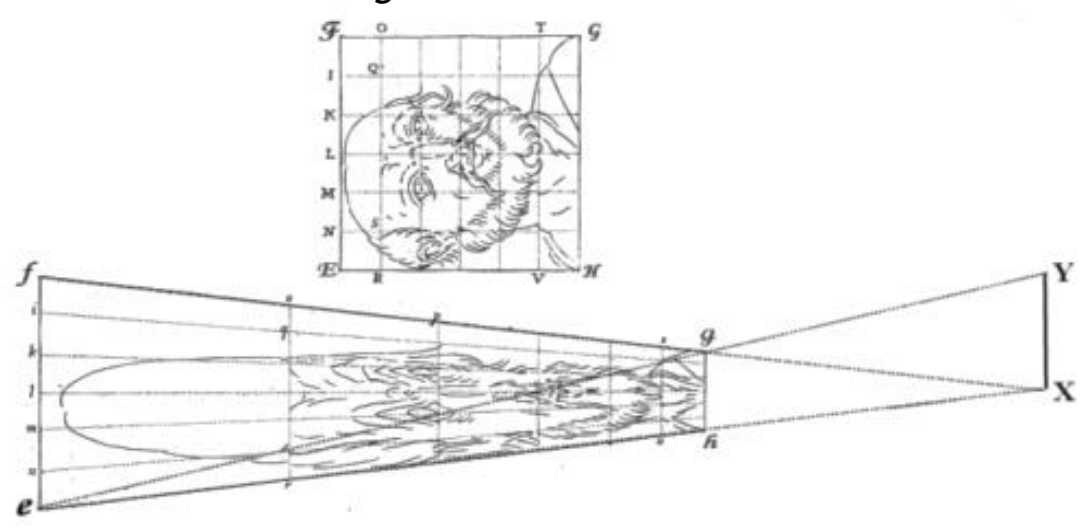

\footnotetext{
3 fonte: <www.chinahighlights.com>. Acesso no dia 18/01/2021.

${ }^{4}$ fonte:www.enea.it/it/seguici/pubblicazioni/EAl/anno-2013/1-2-gennaio-aprile-2013/figurativeart-perception-and-hidden-images-in-inverse-perspective. Acesso em: 18/01/2021.

TradTerm, São Paulo, v.38, fevereiro/2021, p. 194-216

Número Especial - III JOTA

www.revistas.usp.br/tradterm
} 
Em 1645, o matemático, físico e inventor alemão Athanasius Kircher lançou o livro Ars Magna Lucis et Umbrae (Arte Magna de Luz e Sombra) que descrevia uma câmera escura, uma fonte de luz e um jogo de lentes usados para projetarem imagens coloridas em superfícies transparentes. Nascia a Lanterna Mágica que fascinou milhares de crianças e adultos com histórias sobre contos de fadas e fantasmagorias, muitas vezes acompanhadas de narrações e música ao vivo.

Figura 4: Lanterna mágica. ${ }^{5}$

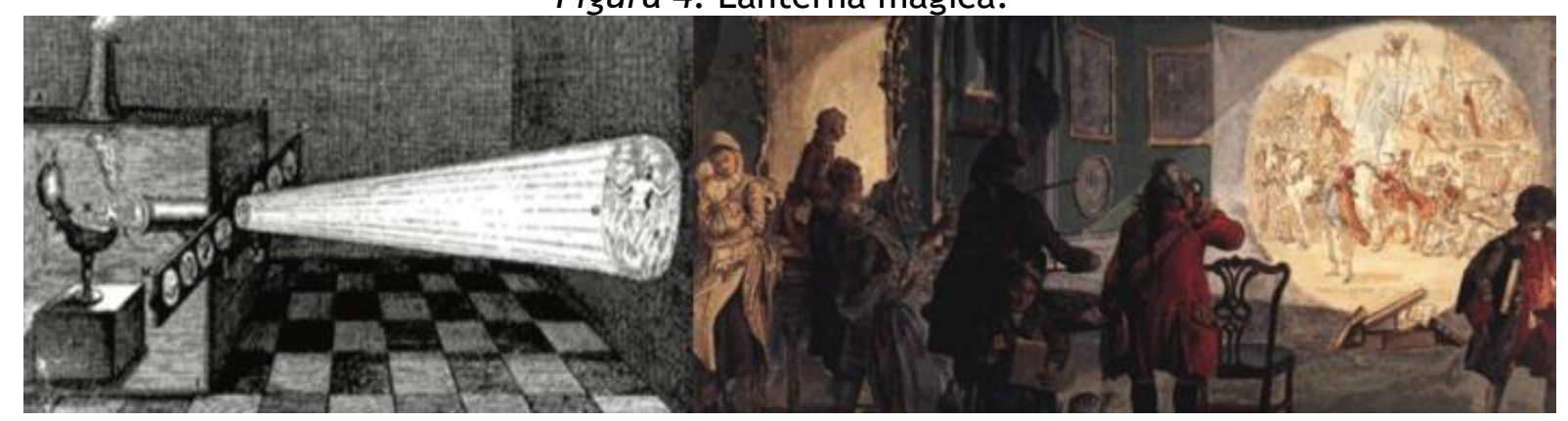

Alguns séculos depois da Lanterna Mágica, o taumatrópio provocava a ilusão do movimento através da fusão de imagens alternadas em velocidade superior à capacidade do discernimento óptico da retina humana. O dispositivo, inventado pelo físico inglês Peter Mark Roget em 1824, se tornaria um brinquedo popular na era Vitoriana e consistia de duas imagens diferentes impressas em cada lado de um disco esférico que, quando girado rapidamente, produzia a impressão de uma sobreposição. Foi esse dispositivo que abriu caminho para toda uma série de invenções que antecipou o surgimento do cinema.

Figura 5: taumatrópio. ${ }^{6}$

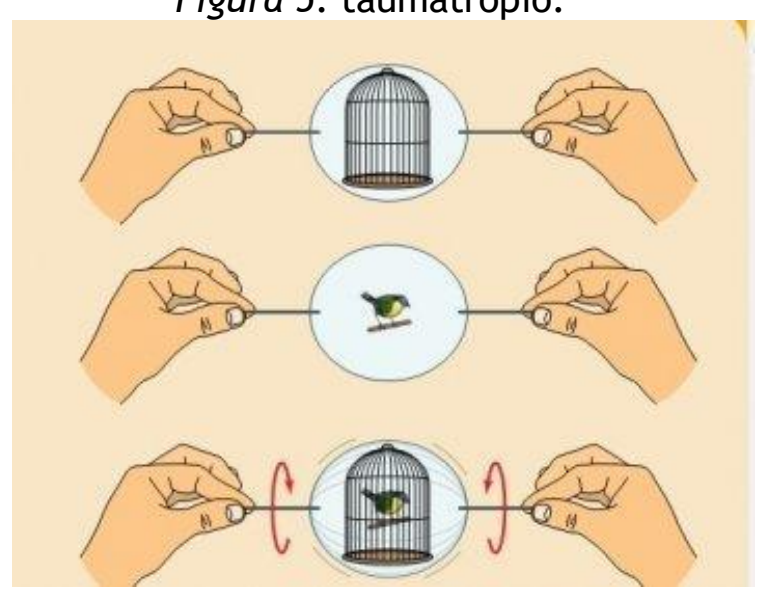

\footnotetext{
${ }^{5}$ fonte: http: / / web.archive.org/web/20201105231904/https://www.magiclanternsociety.org/. Site acessado no dia 21/01/2011.

${ }^{6}$ fonte: https: //www.animationkolkata.com/blog/2016/11/22/evolution-of-animation/. Acesso no dia $18 / 01 / 2021$.

TradTerm, São Paulo, v.38, fevereiro/2021, p. 194-216

Número Especial - III JOTA

www.revistas.usp.br/tradterm
} 
O também britânico John Barnes Linnett aprimorou a invenção de seu compatriota e desenvolveu uma coleção de imagens organizadas sequencialmente e manipuladas geralmente no formato de livreto. Em 1868 surgia o folioscópio, também conhecido por flipbook.

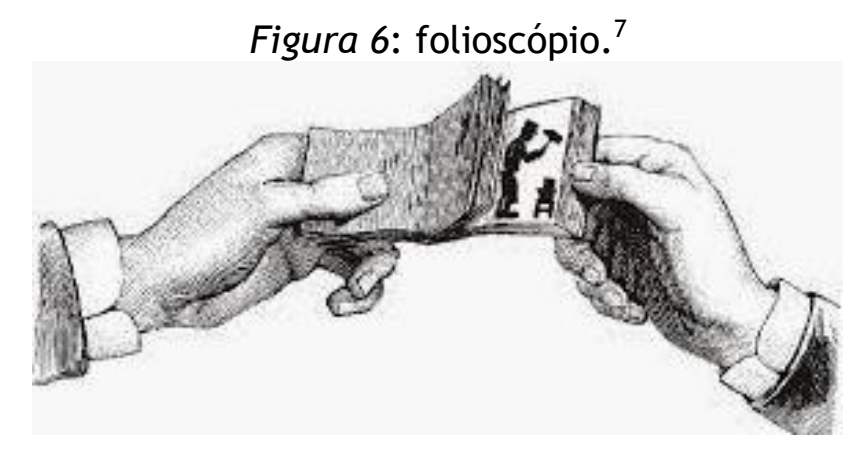

Quase uma década depois, em 1877, o inventor francês Charles-Émile Reynaud criou uma roda cilíndrica com o centro espelhado, que permitia inserir uma série de desenhos em sequência.

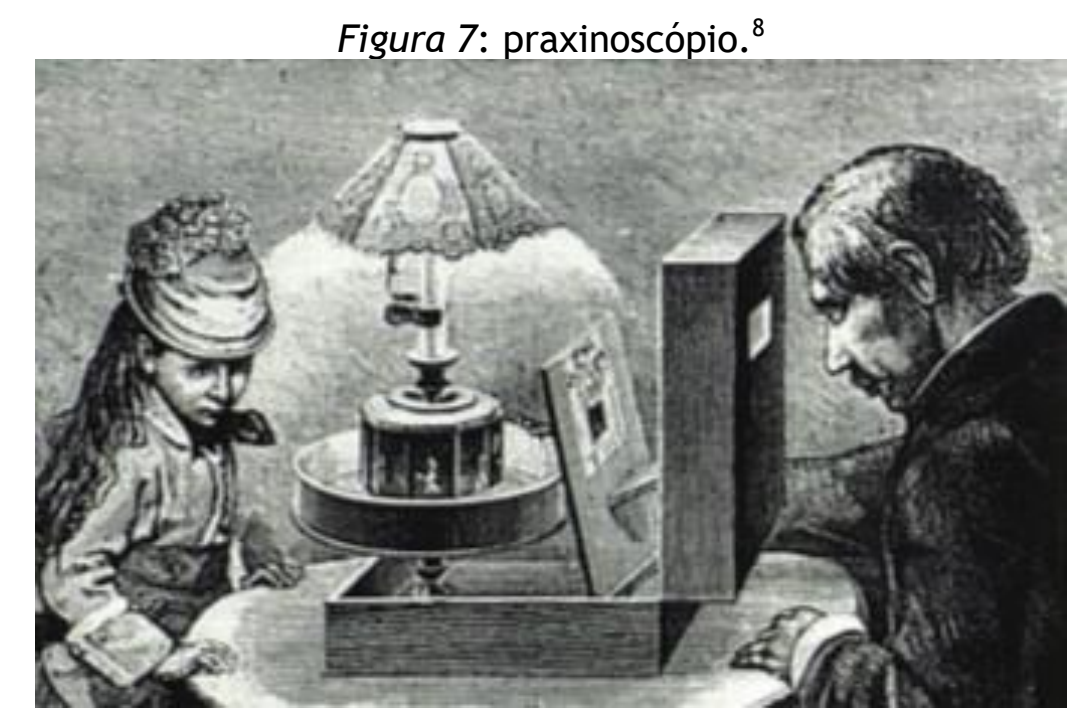

Ao ser girada, a roda promovia a ilusão do movimento. 0 praxinoscópio foi lançado como um brinquedo infantil que se tornou rapidamente grande sucesso comercial, recebendo uma menção especial na Exposição Universal de Paris em 1878. Arlindo Machado (1997: 19) observa que

\footnotetext{
${ }^{7}$ fonte: http: / /www.flipbook.info/history.php. Acesso no dia 18/01/2021.

${ }^{8}$ fonte: http://freaksanimation.blogspot.com/2009/11/historia-da-animacao.htm. Acesso no dia $18 / 01 / 2021$.

TradTerm, São Paulo, v.38, fevereiro/2021, p. 194-216

Número Especial - III JOTA

www.revistas.usp.br/tradterm
} 
não existe, na verdade, uma história do cinema que começa, por exemplo, em 1895, mas uma história das imagens em movimento projetadas em sala escura, que remonta, pelo menos no Ocidente, a meados do século XVII, com a generalização dos espetáculos de lanterna mágica. O cinema, tal como entendemos hoje, não seria senão uma etapa dessa longa história. Se considerarmos que as placas das lanternas já incluíam, desde pelo menos o século XVIII, mecanismos engenhosos para simular o movimentos das figuras na tela (acionados por manivelas ou outros dispositivos cinéticos), recursos de transformação e sobreposição de fontes de luz para produzir fusões e dissolvências, técnicas sofisticadas de roteiros para transformar histórias orais ou escritas em sequências de imagens, sincronização dessas imagens com voz e som, se considerarmos ainda a existência de um público potencial frequentador desses espetáculos, instituições encarregadas de promovêlos e até mesmo a produção semi-industrial de placas transparentes para distribuição em larga escala, devemos forçosamente concluir que o cinematógrafo dos Lumière e de seus outros colegas não chega a representar propriamente um corte [...]. Na virada do século, o cinema provou que era uma invenção com um longo passado e, ao contrário do que dizia Louis Lumière, como bastante futuro.

\section{A Beleza Sombria dos Monstros}

Para discorrermos sobre a transposição dos personagens imagéticos do capítulo Monstros Incompreendidos para os dispositivos do pré-cinema descritos acima e presentes na exposição A Beleza Sombria dos Monstros, nos valeremos das colocações teóricas sobre intermidialidade e transmidialidade de Chiel Kattenbelt (2008), adaptação, de Linda Hutcheon (2006), e remediação, de Jay Bolter e Richard Grusin (2000).

Segundo Kattenbelt (2008: 23),

o conceito de transmidialidade é principalmente usado nos discursos teóricos das artes e comunicações para referir-se à mudança (transposição, tradução, etc) de uma mídia à outra. Essa transferência pode aplicar-se ao conteúdo (ao que é representado, a história) ou à forma (em termos formalísticos, podemos dizer, aos princípios de construção, procedimentos estilísticos e convenções estéticas). No âmbito de conteúdo, o conceito refere-se em particular a mudanças de mídia que se tornam ausentes, por exemplo, à maneira em que características específicas da mídia de origem tornam-se perdidas no processo de transposição. ${ }^{9}$

\footnotetext{
${ }^{9}$ The concept of transmediality is mainly used in art and communication theoretical discourses for referring to the change (transposition, translation etc) from one medium to another. This transfer may apply to the content (to what is represented, the story) or to the form (in formalistic terms we might say to the principles of construction, stylistic procedures and aesthetic conventions). At the

TradTerm, São Paulo, v.38, fevereiro/2021, p. 194-216

Número Especial - III JOTA www.revistas.usp.br/tradterm
} 
Segundo a ótica de Kattenbelt, podemos identificar transmidialidade na exposição A Beleza Sombria dos Monstros no processo de transposição dos personagens de Burton para peças inspiradas nos dispositivos óticos de aspecto artesanal e estética rústica, principalmente por eles (os personagens) assumirem papéis dinâmicos e tridimensionais em dispositivos que remontam a brinquedos educativos para crianças e resgatam antigas técnicas do cinema, perdendo, dessa forma, a condição de imagens estáticas bidimensionais (constantes no livro que derivou a exposição). Tanto a forma quanto o conteúdo são alterados na transposição.

Também como contribuição aos discursos teóricos sobre mídia e arte, o autor afirma que prefere usar o conceito de intermidialidade:

com respeito às correlações entre diferentes mídias que resultam em uma redefinição de mídias que influenciam uma à outra, que, por sua vez, acarretam uma percepção renovada. A intermidialidade assume uma correlação, no sentido real da palavra, que é, por assim dizer, uma influência mútua. Conjuntamente, a redefinição das correlações e uma percepção renovada resultante da correlação das mídias significam que convenções previamente existentes do suporte são alteradas, o que permite novas dimensões de percepção e experiência a serem exploradas. Em afirmar isso, reconheço que intermidialidade é um aspecto operativo de diferentes mídias, a qual é conectada com mais proximidade à ideia de diversidade, discrepância e hipermediação (no sentido de Bolter e Grusin), do que à ideia de unidade, harmonia e transparência (KATTENBELT 2008: 25-26). ${ }^{10}$

Leo Rea Lé, diretor da exposição, ilustra como a ideia de diversidade e discrepância, citada por Kattenbelt, está presente no projeto:

level of the content the concept refers in particular to those media changes which become absent, for example, the way that the specific features of the source medium become lost in the process of transposition (tradução nossa).

10 ... respect to those co-relations between different media that result in a redefinition of the media that are influencing each other, which in turn leads to a refreshed perception. Intermediality assumes a co-relation in the actual sense of the word, that is to say a mutual affect. Taken together, the redefinition of media co-relationships and a refreshed perception resulting from the corelationship of media means that previously existing medium specific conventions are changed, which allows for new dimensions of perception and experience to be explored. In making this claim, I recognise that intermediality is an operative aspect of different media, which is more closely connected to the idea of diversity, discrepancy and hypermediacy (in the sense of Bolter and Grusin) than to the idea of unity, harmony and transparency (tradução nossa).

TradTerm, São Paulo, v.38, fevereiro/2021, p. 194-216

Número Especial - III JOTA

www.revistas.usp.br/tradterm 
A linha curatorial da proposta conceitual e expográfica da exposição não confundir com o conteúdo - fez seguir os desdobramentos criativos da imagem formativa [...], o que, por sua vez, desaguou num processo criativo no qual os capítulos foram dispostos num diagrama, e ali, investiu-se em justaposições associativas entre o tema e o conteúdo do capítulo e nova(s) imagem(ns) formativa(s), criando uma gama enorme de possibilidades ceno-expográficas. Por exemplo, o prefácio do livro "0 garoto do Lago Burbank", que dá conta das referências artísticas e descobertas estéticas de Tim, foi imaginada, a partir das associações desenhadas, como uma caixa de pandora. 0 capítulo 1, Monstros Incompreendidos, que apresenta o universo lúrido e sombrio de suas criaturas foi imaginada como um gabinete de geringonças, e assim seguimos por cada capítulo. Importante dizer que nesse momento, cativados pelo processo e pelas imagens, pretendíamos que a experiência expandida do livro na exposição abandonasse a ordinariedade da estrutura capitular e o recriasse como um mapa, que guiaria o público em descobertas também associativas. Nesse modelo, o prefácio poderia estar ao lado do capítulo 13 - o fim, que por sua vez, estaria ao lado do capítulo $5 .^{11}$

Kattenbelt menciona, também, que intermidialidade pode significar menos consonância e mais digressão. Essa digressão que, nas palavras do autor, está relacionada a "novas dimensões de percepção e experiência", pode ser evidenciada através da relação entre os personagens do livro de Burton e suas respectivas representações na exposição:

a) Edward Scissorhands (1990) em um teatro de sombras;

b) Vincent (1982) em um espelho mágico;

c) Batman (1989), Catwoman (1992) e Penguin (1992) em lanternas mágicas;

d) Jack Skellington (1993) e Sparky (2012) em um conjunto de flipbooks; e

e) Sweeney Todd (2007) em um praxinoscópio.

Se considerarmos a digressão de uma obra derivada de uma original como subversão, e ela ser uma adaptação da original, é interessante notarmos o que Michael Kinney (2013) ressalta entre os pressupostos teóricos de Linda Hutcheon em seu livro Adaptation (2006). Kinney observa que a adaptação tem um poder subversivo pelo qual podemos mudar nossas compreensões culturais, afetando o

${ }^{11}$ Lé, Leo Rea. Entrevista realizada com Leo Rea Lé em 04/09/2020 por Rodrigo Gontijo. Leo Rea Lé foi o produtor executivo da exposição Beleza Sombria dos Monstros: 10 anos da Arte de Tim Burton.

TradTerm, São Paulo, v.38, fevereiro/2021, p. 194-216

Número Especial - III JOTA

www.revistas.usp.br/tradterm 
que sabemos e esperamos. Quando a natureza agradável da repetição e imitação são partes do processo, a mudança é também elemento fundamental dessa adaptação.

Hutcheon, ainda explicitada por Kinney, afirma que "como produto, uma adaptação pode receber uma definição formal, mas como um processo - de criação e recepção - outros aspectos têm que ser considerados". ${ }^{12}$

Os aspectos aos quais a autora se refere são: o que é adaptado, quem é o adaptador, por que algo é adaptado, como é adaptado e onde a adaptação ocorre. Além disso, Hutcheon também afirma que o processo de adaptação envolve tanto (re-) interpretação quanto recriação. Tais fenômenos podem ser classificados também como apropriação e recuperação, dependendo da sua perspectiva. (HUTCHEON 2006: 15-16)

Podemos responder aos questionamentos de Hutcheon quanto ao "por quê" e ao "como" ocorreram as transposições / adaptações dos personagens de Burton na exposição através dos esclarecimentos do produtor Leo Rea Lé, que descreve o evento como uma experiência expandida do livro que guia o público em descobertas também associativas. ${ }^{13}$

Essa nova experiência com os personagens de Burton pode ser evidenciada, por exemplo, na recriação do filme Edward Scissorhands, o qual começa numa noite azulada (tecnicamente chamada de 'noite americana' - quando a cena é filmada de dia com um filtro azul, produzindo uma aparência de uma suposta noite), com sombras intensas e acentuadas. Enquanto os créditos aparecem na tela, vemos fragmentos da casa onde Edward - uma espécie de Frankenstein de um conto de fadas - mora isolado depois de seu criador ter falecido. A ambientação é soturna, marcada por penumbra, silhuetas e obscuridade. Na exposição, a representação desse personagem se deu através de teatro de sombras - que remete à estética do filme. 0 personagem Edward original de Tim Burton teve sua imagem cortada em madeira de MDF. Com discos, correias, arames e engrenagens foi construído um autômato que girava e movimentava as pernas, braços e mãos através de um sistema de motor de baixa rotação, em um cenário com uma árvore

\footnotetext{
${ }^{12}$ As a product, an adaptation can be given formal definition, but as a process - of creation and of reception - other aspects have to be considered (tradução nossa).

${ }^{13}$ Lé, Leo Rea. Entrevista realizada com Leo Rea Lé em 04/09/2020 por Rodrigo Gontijo.

TradTerm, São Paulo, v.38, fevereiro/2021, p. 194-216

Número Especial - III JOTA

www.revistas.usp.br/tradterm
} 
e um castelo em papelão. O autômato era iluminado com lâmpada LED e tinha sua sombra projetada sobre uma tela translúcida de cetim branco. Ao entrar na sala expositiva, o público assistia a projeção grande e imponente, enquanto o mecanismo podia ser visto pelas laterais da tela. O autômato de Edward Scissorhands, ao mesmo tempo que fascinava e instigava o público em um novo suporte, evocava, também, o clima sombrio de sua versão original.

Figura 8: recriação de Edward Scissorhands na exposição A Beleza Sombria dos Monstros. ${ }^{14}$

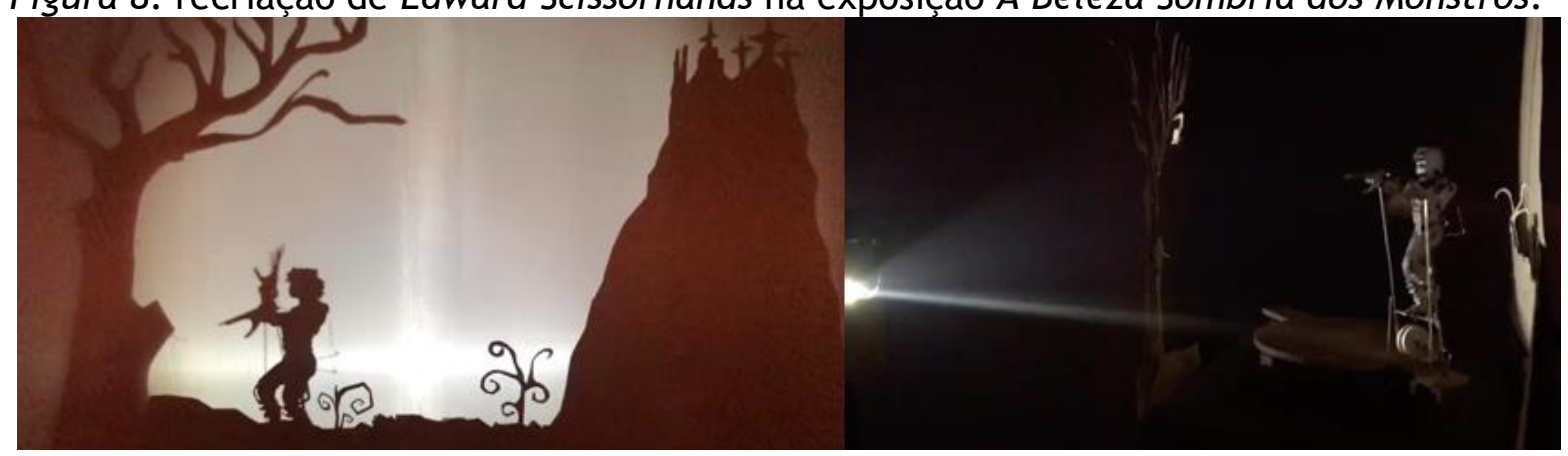

Também em referência ao "por que" e como ocorre a adaptação - quanto ao questionamento de Hutcheon - podemos citar um dispositivo que recriava o personagem Vincent em uma série de figuras distorcidas irreconhecíveis e que, ao ter um espelho cilíndrico posicionado sobre elas, corrigia a imagem e a tornava reconhecida ao observador. Tal artefato evocava mundos sombrios e distorcidos, remetendo a cenários de filmes como Das Cabinet des Dr. Caligari (Robert Wiene, 1920) e Nosferatu (F.W. Murnau, 1922), clássicos do cinema expressionista alemão. O filme de Weine - de estética inovadora com seus cenários de ruas tortas, casas deformadas e paisagens sinuosas, pintadas por artistas expressionistas representava a alma torturada de uma Alemanha pós Primeira Guerra Mundial. A película de Murnau, por sua vez, um intenso jogo entre luz e escuridão, no qual o enorme vampiro ampliado por sua sombra, aterrorizava todos que passam pelo seu caminho.

A estética de sombras e cenários de ambos filmes é incorporada aos devaneios de Vincent, que se imaginava entre morcegos e bonecos de cera e lia contos macabros de Edgar Allan Poe. Como os desenhos de Tim Burton ilustram esses momentos de Vincent, o ponto chave destacado na concepção da exposição

\footnotetext{
${ }^{14}$ fonte: acervo dos autores.

TradTerm, São Paulo, v.38, fevereiro/2021, p. 194-216

Número Especial - III JOTA

www.revistas.usp.br/tradterm
} 
foi a distorção, mesmo efeito provocado por pintores renascentistas do século XV ao experimentarem espelhos arredondados e cilíndricos para criarem fragmentos de distorções em suas obras.

Figura 9: espelho mágico da exposição A Beleza Sombria dos Monstros. ${ }^{15}$

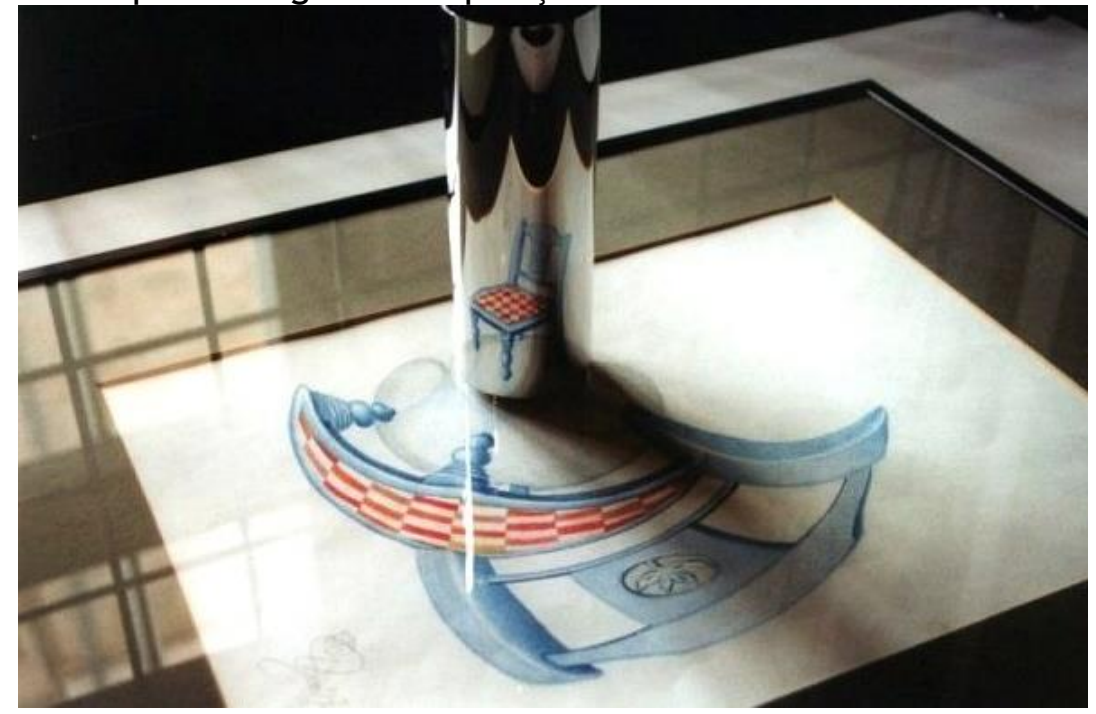

Hutcheon (2006: 142) declara que a adaptação, enquanto produto, apresenta estrutura formal de "tema e variação" ou repetição com diferenças. Isso significa não apenas que a mudança é inevitável, mas que também há múltiplas causas possíveis para alterações ocorridas no processo, sejam elas relevantes ao adaptador, ao público específico, ou aos contextos de recepção e criação.

Figura 10: recursos do espelho mágico da exposição A Beleza Sombria dos Monstros. ${ }^{16}$
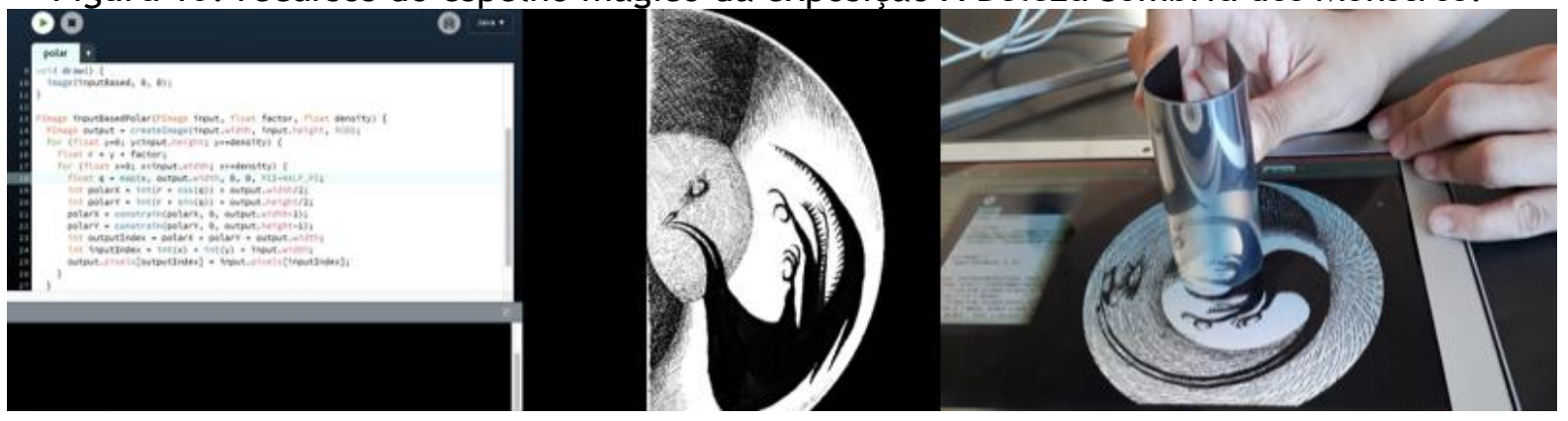

Além dos exemplos citados anteriormente, podemos detectar alterações de convenções e, consequentes a presença de diversidade e discrepância na

\footnotetext{
${ }^{15}$ fonte: acervo dos autores.

16 fonte: acervo dos autores.

TradTerm, São Paulo, v.38, fevereiro/2021, p. 194-216

Número Especial - III JOTA

www.revistas.usp.br/tradterm
} 
materialização dos personagens Batman, Catwoman e Penguin (dos filmes Batman e Batman Returns), corroborando a postulação de Kattenbelt (2008: 25) de que a transmidialidade propicia uma nova dimensão de percepção e experiência a partir da correlação das mídias com a alteração das convenções da mídia originária e o produto resultante da transposição.

Os três personagens (Batman, Catwoman e Penguin) foram concebidos para a exposição em uma lanterna mágica automatizada, inspirada na silhueta luminosa de um morcego projetada nos céus da cidade como aviso ao departamento de polícia de Gotham City. O sistema apresentava uma fonte de luz com a projeção da imagem dos personagens, construído em madeira MDF sobre um tripé, com um dispositivo circular manual para 12 diferentes imagens, que se movimentava de forma autônoma, conforme a ilustração da figura 11.

Figura 11: dispositivo de lanterna mágica na exposição A Beleza Sombria dos Monstros. ${ }^{17}$

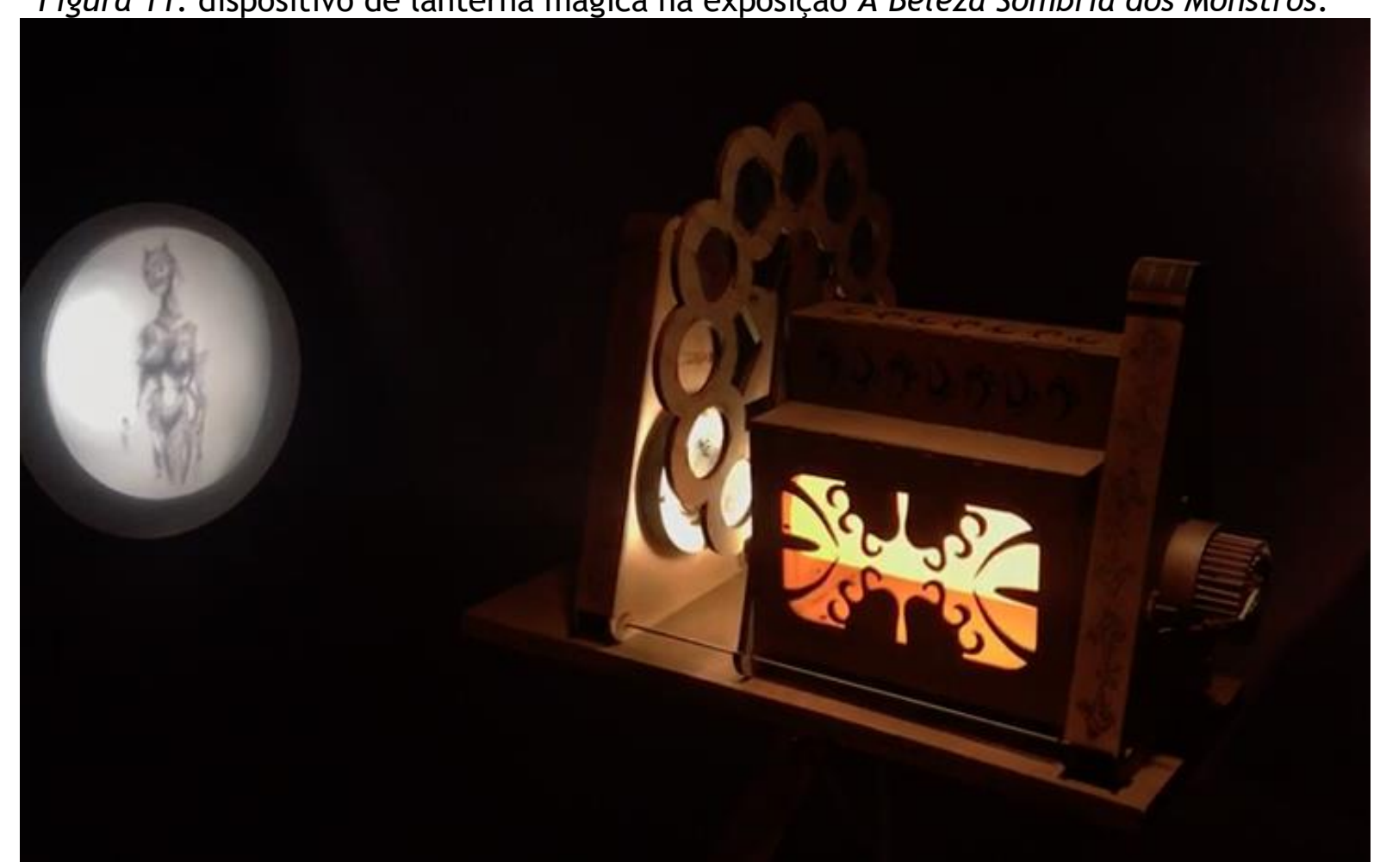

Aqui vale notar o paradigma teórico de Bolter e Grusin em seu Remediation: understanding new media (2000): o histórico da mídia não é uma série de deslocamentos em que novas mídias (como, por exemplo, a Internet) tornam

\footnotetext{
17 fonte: acervo dos autores.

TradTerm, São Paulo, v.38, fevereiro/2021, p. 194-216

Número Especial - III JOTA

www.revistas.usp.br/tradterm
} 
obsoletas as mídias antigas (como, por exemplo, o rádio ou TV), mas sim que essas novas mídias transformam as mídias mais antigas, mantendo alguns de seus recursos e descartando outros. Segundo os autores, o neologismo remediation (remediação) é "a maneira pela qual um meio é visto por nossa cultura como reforma ou aprimoramento de outro" (BOLTER e GRUSIN 2000: 59) ${ }^{18}$, ou "a lógica formal pela qual novas mídias remodelam as formas anteriores de mídia" (idem: $273)^{19}$.

Assim, ao analisarmos a transposição de The Nightmare Before Christmas e Frankenweenie para um flipbook na exposição, podemos afirmar que ocorre exatamente o inverso do prescrito por Bolter e Grusin: uma nova mídia (o cinema moderno) é transportado (ou traduzido) para uma mídia antiga, o flipbook, aparato do pré-cinema que utiliza sequências de imagens organizadas em um pequeno livro com fotografias tiradas em curtos intervalos sequenciais de tempo.

Interessado nas técnicas do primeiro cinema, além de Vincent, Burton realizou outros trabalhos em stopmotion (registro visual quadro a quadro de um objeto inanimado, em mudanças sutis, para simular movimento) como The Nightmare Before Christmas e Frankenweenie.

Mesmo com a evolução da computação gráfica para animações, o diretor norte-americano tem especial afeição por técnicas artesanais do cinema. Inspirados na preferência de Burton, os adaptadores optaram por criarem um tríptico de flipbook mecanizado, no qual os personagens caminham de um objeto para o outro, respeitando a temporalidade do movimento, e permite que eles atravessem os três aparelhos.

Cada engenhoca foi estruturada numa caixa de MDF de $15 \mathrm{~cm} \times 15 \mathrm{~cm}$ com 12 quadros desenhados e, com a ajuda de um motor e engrenagens, fazia com que as cartelas de desenhos passassem em velocidade adequada para criar a ilusão de movimento.

18 ... the way in which one medium is seen by our culture as reforming or improving upon another (tradução nossa)

19 the formal logic by which new media refashion prior media forms (tradução nossa)

TradTerm, São Paulo, v.38, fevereiro/2021, p. 194-216

Número Especial - III JOTA

www.revistas.usp.br/tradterm 
Figura 12: esboço do tríptico de flipbook da exposição A Beleza Sombria dos Monstros. ${ }^{20}$

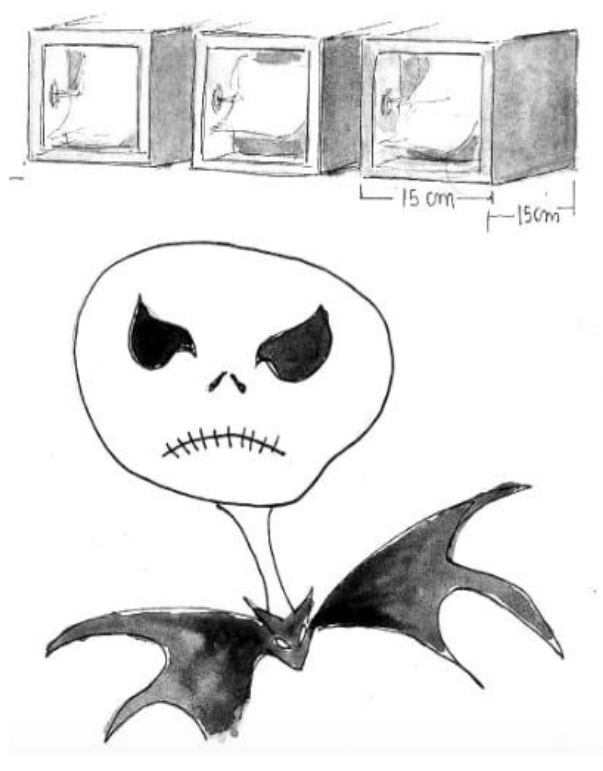

No filme, Jack Skellington, o esqueleto protagonista de The Nightmare Before Christmas, cansado de assustar as pessoas na 'Cidade do Halloween', resolve vagar pela noite e encontra uma passagem que o leva à 'Cidade do Natal'.

A obra referente a Skellington na exposição apresentava três dispositivos que contemplavam diferentes enquadramentos do cinema. 0 primeiro apresentava o personagem em um plano conjunto, de corpo inteiro, caminhando da esquerda para a direita e um céu estrelado ao fundo. O protagonista saía de quadro e, ao entrar no segundo flipbook, era visto um plano próximo a suas pernas, caminhando enquanto passava na frente do túmulo de seu cão Zero, que, por sua vez, seguia o dono até ambos desaparecerem do quadro. No terceiro flipbook, ambos entravam em cena - da esquerda para a direita - e, num plano geral, caminhavam subindo uma colina com uma grande lua cheia ao fundo. 0 outro tríptico de flipbooks representava a cena de um filme dentro do filme, logo no início de Frankenweenie, em que o cachorro Sparky é protagonista. A obra original começava com uma projeção em película, realizado pelo próprio Victor, na qual a técnica stopmotion trazia seus bonecos à vida. No enredo, um monstro voador,

${ }^{20}$ fonte: acervo dos autores.

TradTerm, São Paulo, v.38, fevereiro/2021, p. 194-216

Número Especial - III JOTA www.revistas.usp.br/tradterm 
parecido com um pterodáctilo, atacava uma cidade e o exército não conseguia combatê-lo. É quando surgia Sparky vestido de Sparkysaurus. O cão super-herói vencia o monstro e salvava toda a população.

A cena representada no tríptico de flipbook tinha programação mais sofisticada: a ação começava no dispositivo central com as cartelas de texto, e um monstro aparecia no terceiro flipbook. Sparkysaurus surgia no primeiro mecanismo, atravessava os dois seguintes, saía de quadro e era empurrado para dentro do flipbook novamente. Todas as cenas foram animadas digitalmente a partir dos desenhos originais de Tim Burton, preservando seus traços e características.

Figura 13: Trípticos de flipbooks da exposição A Beleza Sombria dos Monstros. ${ }^{21}$

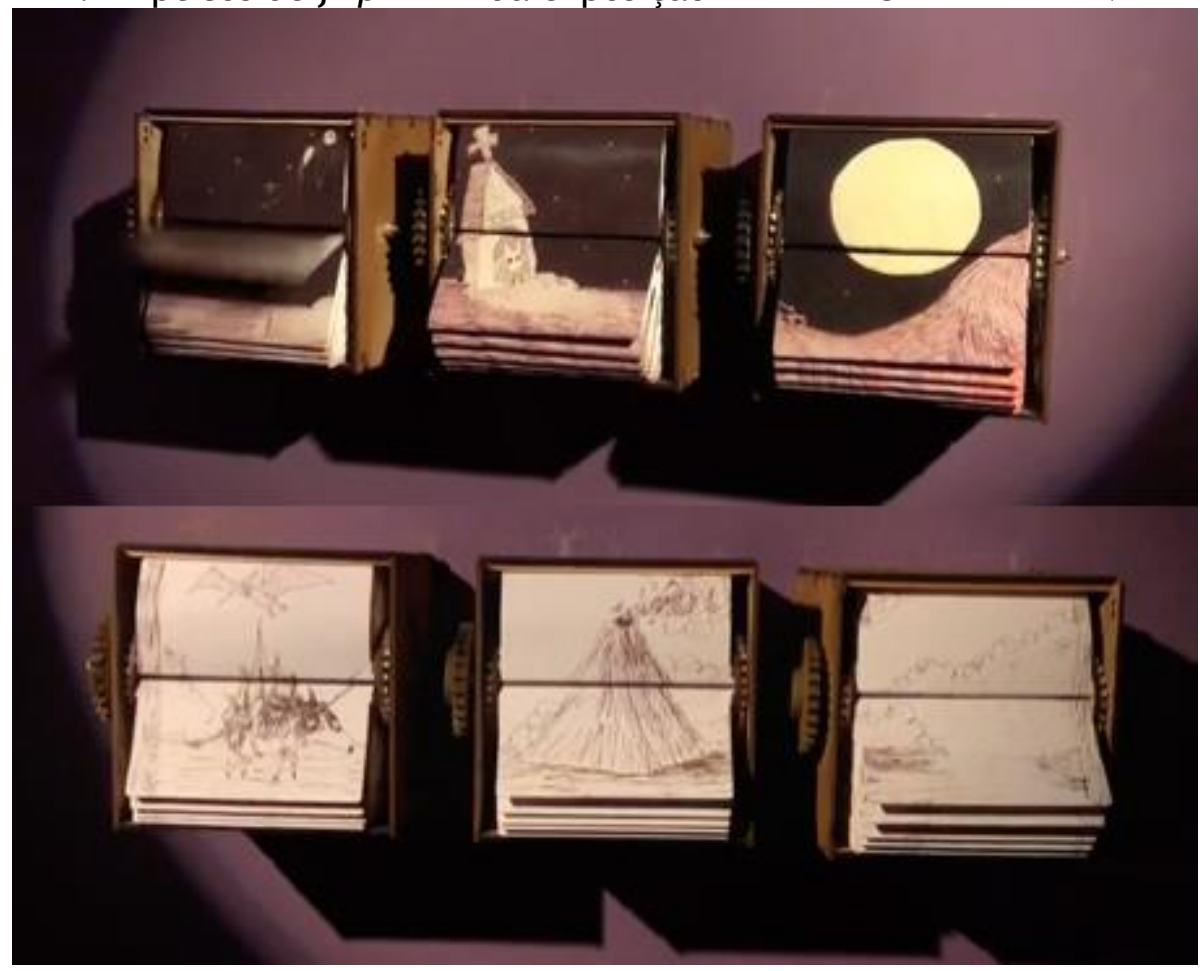

Tim Burton criou uma série de desenhos de um barbeiro sanguinário após assistir ao musical Sweeney Todd: The Demon Barber of Fleet Street, que contava a história do barbeiro Benjamin Barker, mandado injustamente para a Austrália. Ele voltou 15 anos depois como Sweeney Todd para vingar-se do juiz responsável por sua prisão. Ao chegar em Londres, Todd descobria que o magistrado havia se casado com sua mulher e adotado sua filha.

${ }^{21}$ fonte: acervo dos autores.

TradTerm, São Paulo, v.38, fevereiro/2021, p. 194-216

Número Especial - III JOTA

www.revistas.usp.br/tradterm 
Aqui, é interessante recorrermos mais uma vez a Bolter e Grusin (2000) quando afirmam que a remediação é a maneira pela qual um meio é mudança ou aprimoramento de outro. É possível identificar a influência de uma mídia em outra quando o personagem Sweeney Todd foi transposto a um praxinoscópio (uma mídia antiga) com imagens criadas por Burton e que sofria também manipulação digital: o braço do personagem, que segurava uma navalha, se movimentava numa sequência de 12 frames, preservando traços da criação original do autor.

Tal representação também corrobora com o salientado por Hutcheon: para que uma adaptação seja experimentada como uma adaptação, "o reconhecimento da história deve ser possível: faz-se necessária alguma fidelidade na cópia, de fato, precisamente por causa das mudanças nas mídias e nos contextos" (2006: 167). ${ }^{22}$

Num esforço para as relações associativas com a obra inicial serem mantidas, imagens originais foram inseridas no praxinoscópio estilizado e mecanizado. A primeira dessas relações associativas que o público experimentava era observar figuras através dos espelhos centrais do dispositivo, um objeto que, quando quebrado, se tornaria cortante. A segunda é a alusão ao ataque de fúria de Charles-Émile Reynaud, o inventor do dispositivo, quando ele próprio o atirou nas águas do rio Sena, ao perceber que seu invento havia sido preterido pelo cinematógrafo que acabara de surgir. A agressividade em torno da história do dispositivo correspondia à hostilidade vivida pelo personagem principal de Sweeney Todd: The Demon Barber of Fleet Street.

22 ... recognition of the story has to be possible: some copying-fidelity is needed, in fact, precisely because of the changes across media and contexts (tradução nossa).

TradTerm, São Paulo, v.38, fevereiro/2021, p. 194-216

Número Especial - III JOTA

www.revistas.usp.br/tradterm 
Figura 14: praxinoscópio da exposição A Beleza Sombria dos Monstros. ${ }^{23}$

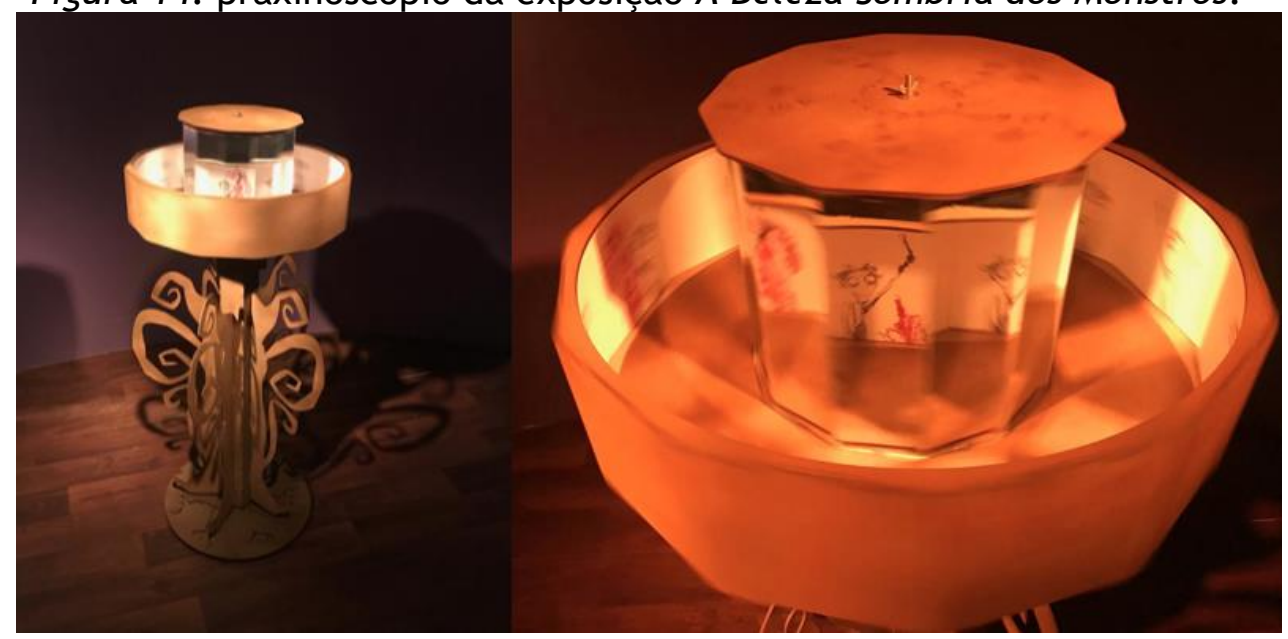

\section{A receptividade do público}

Os desenhos do livro The Art of Tim Burton, realizados como estudos de personagens que viriam a ser protagonistas de filmes futuros, uma vez transportados à exposição, voltam ao passado, resgatam a história do cinema e ganham movimento em dispositivos óticos mecanizados.

Diferentemente das demais salas da exposição $A$ Beleza Sombria dos Monstros: 10 anos da Arte de Tim Burton, que ofereciam óculos de realidade virtual, projeções mapeadas e tridimensionais, a sala Monstros Incompreendidos se destacou e teve comentários e críticas positivas por parte do próprio Tim Burton, das curadoras, da imprensa e do público. 0 diretor norte-americano ficou particularmente feliz, pois a instalação o fez reviver momentos da infância. Quanto ao público, houve quem ficou impressionado com a capacidade de os desenhos criarem a ilusão do movimento; outros, eram instigados a discutir as origens do cinema, enquanto outros, ainda, se maravilharam com a simplicidade e beleza das peças e com o efeito que elas causavam.

\section{Considerações Finais}

Nesta pesquisa foi proposto o estudo da transposição do primeiro capítulo (Monstros Incompreendidos) do livro The Art of Tim Burton para a sala expositiva

\footnotetext{
${ }^{23}$ fonte: acervo dos autores.

TradTerm, São Paulo, v.38, fevereiro/2021, p. 194-216

Número Especial - III JOTA

www.revistas.usp.br/tradterm
} 
Monstros Incompreendidos da exposição A Beleza Sombria dos Monstros, idealizada por artistas brasileiros, com curadoria de Jenny He, Holly Kempf e direção de Leo Rea Lé.

$\mathrm{Na}$ primeira parte da pesquisa, descrevemos as instalações presentes na exposição, bem como a estética de pré-cinema que as caracterizou. Na etapa seguinte, buscamos confrontar o processo de transposição dos personagens imagéticos do livro para os dispositivos do pré-cinema com as colocações teóricas sobre intermidialidade e transmidialidade de Chiel Kattenbelt (2008), sobre adaptação de Linda Hutcheon (2006) e remediação de Jay Bolter e Richard Grusin (2000).

Assim como as considerações do produtor executivo do projeto Leo Rea Lé, o arcabouço teórico dos autores citados foi fundamental para que escrutinássemos os elementos artísticos da exposição. Como apontado por um dos autores desta pesquisa - que também participou como artista criador das obras - tanto o diretor norte-americano Tim Burton, quanto o público participante, tiveram uma impressão positiva do conjunto das peças artísticas presentes na sala Monstros Incompreendidos.

TradTerm, São Paulo, v.38, fevereiro/2021, p. 194-216

Número Especial - III JOTA

www.revistas.usp.br/tradterm 


\section{Referências}

BolteR, J.; Grusin, R. Remediation: Understanding new media. MIT Press, 2000.

BURTOn et al., The Art of Tim Burton. Steeles Publishing, 2009

BURTON, T. The Napkin Art of Tim Burton. Steeles Publishing, 2015

GIL, J. Metafenomenologia da Monstruosidade: o Devir-monstro. In: DonALD, J;

GIL, J.; Hunter, I.; COHEN, J.; SILVA, T. (org). Pedagogia dos Monstros - Os Prazeres e os Perigos da Confusão de Fronteiras. Belo Horizonte: Autêntica, 2000.

HutCheon, L. A Theory of Adaptation. New York: Routledge, 2006.

Kattenbelt, C. Intermediality in Theatre and Performance: Definitions, Perceptions and Medial Relationships. Culture, Language and representation, v. VI, 2008, p. 19-29.

KINNEY, M. Critical Voices. The University of Guelph Book Review Project, v. 3, n. 3, 2013.

Machado, A. Pré Cinema \& Pós Cinema. Campinas: Papirus Editora, 1997.

Mascarello, F. (ed.). História do Cinema Mundial. Papirus Editora, 2006.

Recebido em: 15/04/2020

Aceito em: 22/09/2020

Publicado em fevereiro de 2021

TradTerm, São Paulo, v.38, fevereiro/2021, p. 194-216

Número Especial - III JOTA

www.revistas.usp.br/tradterm 